\title{
Spermatogonial asynchrony in Tex14 mutant mice lacking intercellular bridges
}

\author{
C A Rezende-Melo ${ }^{1,2}$, A L Caldeira-Brant ${ }^{1}$, A L Drumond-Bock $\mathbb{1}^{3}$, G M Buchold ${ }^{4}$, \\ G Shetty ${ }^{5}$, F R C L Almeida ${ }^{1,2}$, M M Matzuk ${ }^{6}$, K Hara ${ }^{7,8,9}$, S Yoshida7,8, M L Meistrich ${ }^{5}$ and \\ H Chiarini-Garcia ${ }^{1}$
}

'Laboratory of Structural Biology and Reproduction, Department of Morphology, Institute of Biological Sciences, Federal University of Minas Gerais, Belo Horizonte, Minas Gerais, Brazil, ${ }^{2}$ Faculty of Graduate Studies in Animal Science, Veterinary School, Federal University of Minas Gerais, Belo Horizonte, Minas Gerais, Brazil, ${ }^{3}$ Department of Aging \& Metabolism, Oklahoma Medical Research Foundation, Oklahoma City, Oklahoma, USA, ${ }^{4}$ Sheikh Khalifa Zayed Al Nahyan Institute for Personalized Cancer Therapy, University of Texas, MD Anderson Cancer Center, Houston, Texas, USA, ${ }^{5}$ Department of Experimental Radiation Oncology, University of Texas, M.D. Anderson Cancer Center, Houston, Texas, USA, ${ }^{6}$ Center for Drug Discovery and Department of Pathology \& Immunology, Baylor College of Medicine, One Baylor Plaza, Houston, Texas, USA, ${ }^{7}$ Division of Germ Cell Biology, National Institute for Basic Biology, National Institutes of Natural Sciences, Okazaki, Japan, ${ }^{8}$ Department of Basic Biology, School of Life Science, Graduate University for Advanced Studies (Sokendai), Okazaki, Japan and ${ }^{9}$ Laboratory of Animal Reproduction and Development, Graduate School of Agricultural Science, Tohoku University, Sendai, Japan

Correspondence should be addressed to H Chiarini-Garcia; Email: heliochiarini@gmail.com

\begin{abstract}
The existence of cytoplasmic passages between germ cells and their potential function in the control of the spermatogenic process has long been an intriguing question. Evidence of the important role of such structures, known as intercellular bridges (ICB), in spermatogenesis has been implicated by the failure of spermatogenesis in testis-expressed gene 14 (Tex14) mutant mice, which lack the ICBs, to progress past the pachytene spermatocyte stage. Using these Tex14 mutants, the present study evaluated, for the first time, the behavior and synchrony of the spermatogonial lineage in the absence of ICBs. Our data suggest that the absence of these cytoplasmic connections between cells affects the expansion of the undifferentiated type $A\left(A_{\text {undiff }}\right)$ spermatogonia compartment and their transition to $A_{1}$, resulting in a significant numerical reduction of differentiating $A_{1}$ spermatogonia, but did not interfere with cell amplification during subsequent mitotic steps of differentiating spermatogonia from $A_{1}$ through intermediate (In). However, beginning at the type $B$ spermatogonia, the synchrony of differentiation was impaired as some cells showed delayed differentiation compared to their behavior in a normal seminiferous epithelium cycle. Thus although spermatogonial development is able to proceed, in the absence of ICBs in Tex14-/- mutants, the yield of cells, specific steps of differentiation, the synchrony of the cell kinetics, and the subsequent progression in meiosis are quantitatively lower than normal.
\end{abstract}

Reproduction (2020) $\mathbf{1 6 0} 205-215$

\section{Introduction}

Intercellular bridges (ICBs) are cytoplasmic channels that interconnect clones of germ cells in a syncytium. These ICBs remain after the germ cells undergo cytokinesis at the end of both mitotic (Moens \& Hugenholtz 1975) and meiotic (Weber \& Russell 1987) divisions. They can connect hundreds of differentiating germ cells that belong to a single clonal cohort originated from a single stem cell (Huckins 1978).

The precise role of the ICBs has not yet been determined. It has been predicted that the ICBs are involved in the communication and synchronization of germ cells within a syncytium (Dym \& Fawcett 1971) or transit of essential signals for the synchronous cell divisions (Huckins \& Oakberg 1978). The size of a single chain of rat spermatids connected by ICBs is as large as synchronous segments (stages) along the length of seminiferous tubules, supporting the role of ICBs in the synchrony (Ren \& Russell 1991). In addition, a role for the ICBs has been proposed for the chromosome dosage compensation between haploid germ cells since movement of mRNA (Braun et al. 1989, Morales et al. 2002) and organelles (Ventela et al. 2003) were observed between spermatids. Furthermore, the regulation of the germ cell number in the testis by the transit of apoptotic signaling substances along a clone of differentiating 
spermatogonia has been attributed to these structures (Hamer et al. 2003).

The testis-expressed gene 14 (Tex14) codes for a protein that is a structural component of the ICBs and is expressed in germ cells from undifferentiated type $A$ $\left(\mathrm{A}_{\text {undiff }}\right)$ spermatogonia through step 9 spermatids $(\mathrm{Wu}$ etal. 2003, Greenbaum etal. 2006). Tex14 knockout mice $\left(\right.$ Tex $\left.14^{-/-}\right)$were generated and in electron microscope or immunofluorescence studies, no ICBs could be detected in these mice. Despite the fact that the formation of ICBs in the transition of $A_{\text {undiff }}$ spermatogonia from $A_{\text {single }}$ to $A_{\text {paired }}$ and $A_{\text {aligned }}$ spermatogonia has traditionally been considered to be the morphological hallmark of stem to progenitor cell transition (de Rooij 2017), in the absence of ICBs the spermatogonia still undergo selfrenewal, progress through differentiation and mitotic amplification, and initiate meiosis in Tex $14^{-/-}$mice. Later stage germ cells were severely depleted and the most advanced type found was pachytene spermatocytes (Greenbaum et al. 2006). In addition, in short-term spermatogonial stem cell culture, cells prepared from Tex $14^{-/-}$mice could proliferate, giving rise to short chains (Iwamori et al. 2012).

Although the effects of TEX14 deficiency in spermatogenesis have been characterized in part, its impact on the proliferative phase of the spermatogenesis, which starts with the spermatogonial stem cells (SSCs) and culminates with the formation of preleptotene spermatocytes, has not been evaluated. Furthermore, the effect of TEX14 deficiency on the precise synchronization of the seminiferous epithelium has not been directly addressed. Therefore, the present study investigated the spermatogonial morphology, kinetics, proliferation, synchrony through high-resolution light microscopy (HRLM) and spermatogonial gene expression by immunofluorescence.

\section{Materials and methods}

\section{Animals}

Tex $14^{+/-}$and Tex $14^{-/-}$mice (129/C57 background) were bred and maintained at Baylor College of Medicine (Greenbaum et al. 2006) and used for all histological section studies. Ngn3-EGFP mice (Yoshida et al. 2004) were bred with Tex14 mutant mice to obtain Tex $14^{-/-}$; Ngn3-EGFP male offspring, in the $\mathrm{C} 57 \mathrm{BL} / 6$ background in the National Institute of Basic Biology (Okazaki, Japan) and used for whole mount tubule studies. The experiments performed on mice in these studies were executed in accordance with institutional animal care guidelines and were approved by the Institutional Animal Care and Use Committees of both Baylor College of Medicine and National Institutes of Natural Sciences.

\section{Histological procedures}

Three Tex $14^{+/-}$and four Tex $14^{-/-}$mutant mice at 12 weeks of age were processed for high-resolution light microscopy
(HRLM) (Chiarini-Garcia \& Meistrich 2008). Briefly, the mice were perfusion-fixed via the cardiac route with $5 \%(\mathrm{v} / \mathrm{v})$ glutaraldehyde. Fragments were post-fixed in osmium tetroxide, embedded in Araldite resin, and one- $\mu$ m thick sections were stained with toluidine blue. Using HRLM, we were able to distinguish undifferentiated $A$ spermatogonia $\left(A_{\text {undiff }}\right)$, and each differentiated type, $A_{1}, A_{2}, A_{3}, A_{4}$, intermediate (In), and type $B$ (Chiarini-Garcia \& Russell 2001).

\section{Bromodeoxyuridine (BrdU) labeling}

Two Tex $14^{+/-}$and four Tex $14^{-/-}$8-week-old mice received intraperitoneal injection of BrdU $(60 \mathrm{mg} / \mathrm{kg}$ body weight; Sigma, B5002). One hour later the testes were removed, fixed in $70 \%$ ethanol, embedded in glycol methacrylate (Historesin, Leica), and 5- $\mu \mathrm{m}$ thick sections were immunostained for BrdU (Chiarini-Garcia et al. 2011). Briefly, the slides were sequentially treated with $\mathrm{H}_{2} \mathrm{O}_{2}$, protease and $2 \mathrm{~N} \mathrm{HCl}$ for antigen retrieval. The slides were incubated with BrdU antibody (B44, BD Biosciences); for negative controls, primary antibody was omitted. After incubation with secondary biotinylated antibody, sections were treated with the $A B C$ kit (Vector Laboratories) reagents.

\section{Spermatogonial stages of the seminiferous epithelium}

As spermatids were rarely seen in Tex $14^{-/-}$mice, it was not possible to use the standard acrosomal system method for determining the stages of the seminiferous epithelium cycle (Russell et al. 1990). Instead, we used the method proposed by Huckins and Oakberg (1978), based on the six generations of differentiating spermatogonial subtypes (i.e., $A_{1}, A_{2}, A_{3}, A_{4}$, In and $B$ ), which can be distinguished with confidence using HRLM (Fig. 1). Based on the major subtype of differentiating spermatogonia present, tubules were assigned to stages (1-6). Since there was asynchrony of spermatogonia in the Tex $14^{-/-}$ mice, in cases where equal numbers of two adjacent cell types were observed, the stage was defined by the more advanced one, and in cases where $B$ spermatogonia were present in tubules with $A_{1}$ or $A_{2}$ spermatogonia, the stage was defined by the type $A$ spermatogonia.

\section{Germ cell number}

The numbers of each spermatogonial subtype and spermatocytes were counted in approximately 20 seminiferous tubule cross-sections in each of the six spermatogonial stages, per animal and for each genotype. The numbers of cells were corrected for section thickness and their specific nuclear diameter (Abercrombie 1946). Next, the number of Sertoli cell nucleoli (SCN) was counted and corrected by the same method, and the numbers of each germ cell were normalized per $100 \mathrm{SCN}$.

\section{Germ cell mitosis, labeling index and apoptosis}

Spermatogonial mitotic divisions were identified on slides prepared for HRLM as cells with condensed nuclear chromatin, from the late prophase through early telophase 


\begin{tabular}{|c|c|c|c|c|c|}
\hline $\begin{array}{l}\mathrm{P} \\
\mathrm{P}\end{array}$ & $\begin{array}{l}P \\
P\end{array}$ & $(\mathrm{D}, \mathrm{M} 1, \mathrm{M} 2)$ & & & \\
\hline $\begin{array}{l}\text { B } \\
\text { PI }\end{array}$ & $\begin{array}{l}\mathrm{B}, \mathrm{PI} \\
\mathrm{L}, \mathrm{Z}\end{array}$ & $\begin{array}{l}\mathrm{PI}, \mathrm{L} \\
\mathrm{Z}, \mathrm{P}\end{array}$ & $\begin{array}{l}Z \\
P\end{array}$ & $\begin{array}{l}Z \\
P\end{array}$ & $\begin{array}{l}P \\
P\end{array}$ \\
\hline $\mathrm{A}_{1}$ & $\mathrm{~A}_{2}$ & $\mathrm{~A}_{3}$ & $\mathrm{~A}_{4}$ & $\ln$ & B \\
\hline $\begin{array}{c}\text { Aundiff } \\
\left(\mathrm{As}_{\mathrm{s}} \mathrm{Apr}\right)\end{array}$ & $\begin{array}{c}\text { Aundiff } \\
(\mathrm{As}, \mathrm{Apr})\end{array}$ & $\begin{array}{c}\text { Aundiff } \\
\left(\mathrm{As}, \mathrm{Apr}_{\mathrm{pal}}\right)\end{array}$ & $\begin{array}{c}\text { Aundiff } \\
(\text { As, Apr,Aal) }\end{array}$ & $\begin{array}{c}\text { Aundiff } \\
\left(A_{s,}, A_{p r}, A a l\right)\end{array}$ & $\begin{array}{c}\text { Aundiff } \\
\left(A_{s}, A_{p r}, A a l\right)\end{array}$ \\
\hline 1 & 2 & 3 & 4 & 5 & 6 \\
\hline \multicolumn{6}{|c|}{ Spermatogonial Stages } \\
\hline $\begin{array}{c}\text { Late VII } \\
\text { Middle IX }\end{array}$ & $\begin{array}{c}\text { Late IX } \\
\text { Middle XI }\end{array}$ & $\begin{array}{l}\text { Late XI } \\
\text { Middle I }\end{array}$ & $\begin{array}{c}\text { Late I } \\
\text { Middle II-III }\end{array}$ & $\begin{array}{l}\text { Late II } \\
\text { Middle V }\end{array}$ & $\begin{array}{c}\text { Late V } \\
\text { Middle VII }\end{array}$ \\
\hline \multicolumn{6}{|c|}{ Comparable Acrosome Stage } \\
\hline
\end{tabular}

Figure 1 Cell generations arranged according to the spermatogonial stages (Arabic numerals) of the seminiferous epithelium cycle in mice based on description of Huckins and Oakberg (1978) and comparable acrosomal (Roman numerals) stages (Russell et al. 1990). The chain sizes of the undifferentiated spermatogonia and the meiotic phases seen in normal mice are indicated in parentheses. Cell types in red letters are ones positioned in abnormal stages in Tex $14^{-/-}$mice. Pachytene spermatocytes labeled in green always show degenerating forms in Tex $14^{--}$mice at these stages. $A_{1}, A_{2}, A_{3}, A_{4}$, type $A$ differentiating spermatogonia; In and $\mathrm{B}$, intermediate and type B spermatogonia; $\mathrm{Pl}$, preleptotene; $\mathrm{L}$, leptotene; Z, zygotene; P, pachytene and D, diplotene spermatocytes. M1/M2, meiotic divisions.

stages, located on or near to basal lamina. The numbers of mitotic spermatogonia were normalized per 100 SCN.

Apoptotic spermatogonia and spermatocytes were identified by condensed and fragmented chromatin. They were distinguished by the granularity of chromosome fragmentation (finely granular in spermatogonia and coarsely granular in spermatocytes), the size and shape of the nuclei (small and flattened in spermatogonia and larger and rounded in spermatocytes) and their positions in relation to the basal lamina (apoptotic spermatogonia were near the basal lamina). The numbers of apoptotic spermatogonia were counted in approximately 20 seminiferous tubule cross-sections, in each of the 6 spermatogonial stages, per animal and for each genotype, and normalized per 100 SCN.

The BrdU labeling indices of spermatogonia were assessed in 40 cross-sections of seminiferous tubules per animal and genotype. As a spermatogonial subtypes could not be confidently distinguished in the methacrylate embedded material, spermatogonial staging was not possible. The total spermatogonial labeling index was determined by dividing the number of labeled spermatogonia by the total number of spermatogonia. Next, to estimate the synchrony of BrdUlabeled spermatogonia in the testis, tubules were divided into eight categories with equal ranges of labeling index (i.e. $0-12.5 \%, 12.5-25 \%$, etc.) and the percentages of tubules in each category were determined. Tubules with highly synchronous spermatogonial progression through the cell cycle would have either very high (synchronized in S-phase) or very low labeling indices (synchronized in G2/M/G1 phases); hence, the occurrence of tubules with intermediate labeling indexes indicates asynchrony.

\section{Whole-mount tubule immunostaining}

Tex $14^{+/+} ;$Ngn3-EGFP and Tex14/-;Ngn3-EGFP mice at 7 weeks of age were dissected and fixed in $4 \%$ paraformaldehyde in PBS, attached to MAS-coated glass slides (Matsunami, Osaka, Japan) by half-drying, and used for immunofluorescence, as previously described by (Nakagawa et al. 2010). The following primary antibodies were used: polyclonal anti-GFP Ab (1:300;
Thermo Fisher), polyclonal anti-GFR $\alpha 1$ Ab (1:1000; R\&D systems, MN, USA), and monoclonal anti-Kit Ab (1:200; BD Biosciences). Appropriate secondary antibodies conjugated with Alexa-Fluor 488- or Alexa-Fluor 594 were used. For nuclear staining, Hoechst 33342 (1:5000; Thermo Fisher) was used.

\section{Statistical analysis}

All data are plotted as mean \pm S.E.M. Where error bars are not visible, they are smaller than the symbol for the point representing the mean.

The values obtained in the two genotypes were compared using an independent samples $t$-test, using $P<0.05$ as the criterion for significance unless otherwise noted. When comparisons were made between multiple stages, a one-way ANOVA was performed and significant differences between stages were determined by the post hoc Tukey test. When data were not normally distributed (apoptotic index), a nonparametric Mann-Whitney $U$ test was employed. All analyses were performed using the SPSS 17.0 software.

\section{Results}

\section{Germ cell location}

In this study we focused on the spermatogonia and early spermatocytes, which were present in both Tex $14^{+/-}$heterozygotes and Tex $14^{-1-}$ mutant mice. Using HRLM preparative techniques, we observed that spermatogonial subtypes in both Tex $14+/^{-}$and Tex $14^{-/-}$ mice were morphologically similar to those described previously in wild-type (WT) mice (Chiarini-Garcia \& Russell 2001). In Tex $14^{+/-}$heterozygotes, like in wildtype, undifferentiated type $A\left(A_{\text {undiff }}\right)$ and differentiating $\left(A_{1}\right.$ through $\left.B\right)$ spermatogonia were attached the basal lamina of the seminiferous tubules (Fig. 2A) (Russell 1977). In Tex $14^{-/-}$mice, type $A$ and In spermatogonia were also positioned close to the basal lamina, but some 

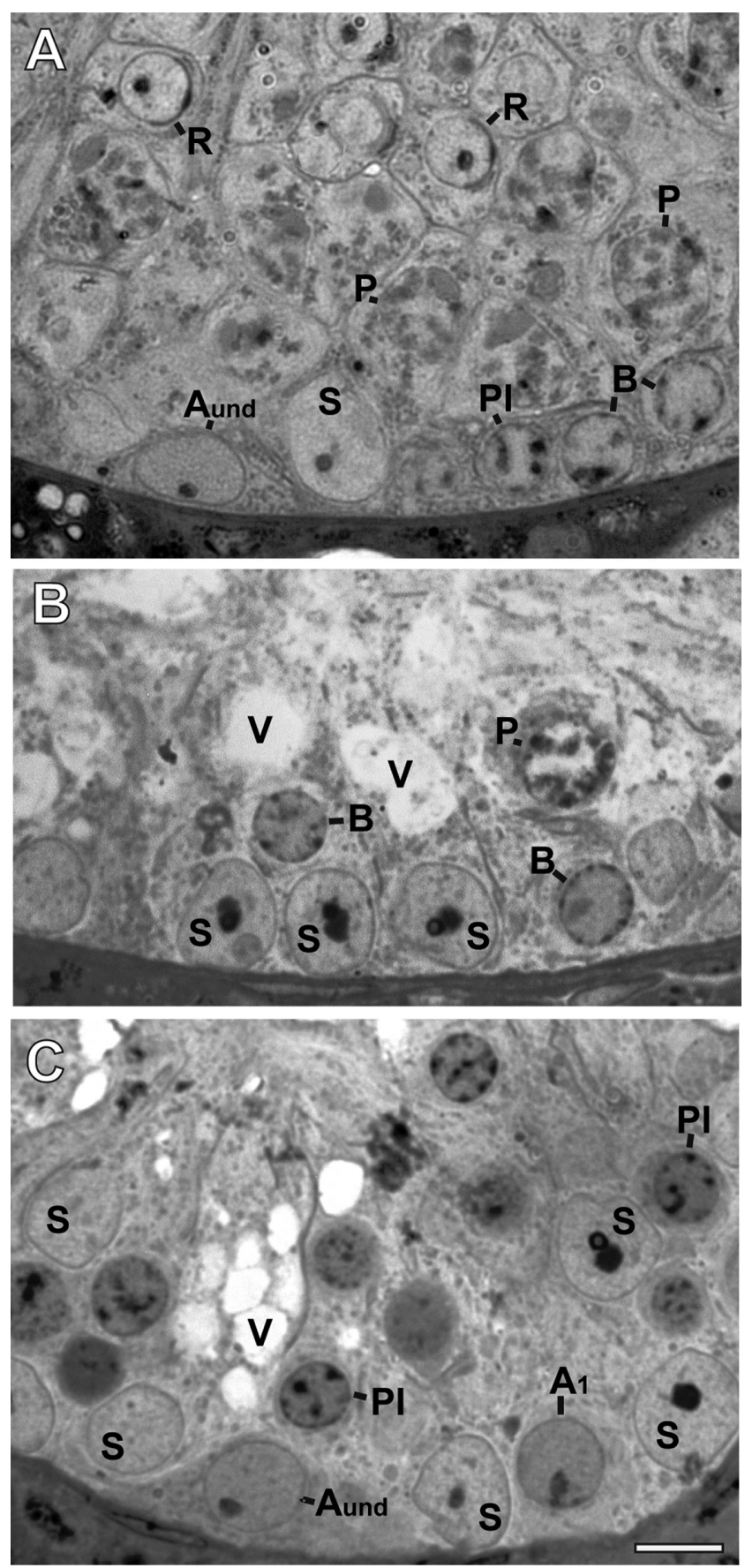

Figure 2 Photomicrographs of portions of testis tubules from a Tex $14^{+/-}$heterozygous mouse at the transition between stages 6 and 1 (A), and from a Tex $14^{\%}$ mutant mouse at stage 6 (B) and at stage 1 (C), showing morphological detail of germ and Sertoli cells. Note that in both genotypes, type $A$ undifferentiated spermatogonia ( $\left.A_{\text {undiff }}\right)$ are appropriately in contact with the basal lamina. Although in the heterozygotes, the B spermatogonia and most preleptotene spermatocytes are also at the basal lamina, in the Tex $14^{-/}$mutants, some type $B$ spermatogonia and most preleptotene spermatocytes are displaced in a luminal direction. B, type B spermatogonia; PI, preleptotene spermatocyte; $\mathrm{P}$, pachytene spermatocyte; $\mathrm{R}$, round spermatid; S, Sertoli cell, V, vacuole. Bar: $8 \mu \mathrm{m}$. type B spermatogonia (Fig. 2B) and many preleptotene spermatocytes (Fig. 2C) were seen atypically dislocated in more adluminal positions.

\section{Germ cell number}

Spermatogenesis appeared normal in heterozygous Tex $14^{+/}$mice and the numbers of undifferentiated and differentiating spermatogonia (Fig. 3) were similar to that observed previously in WT mice (Tegelenbosch \& de Rooij 1993). There were significant differences in the numbers of $\mathrm{A}_{\text {undiff }}$ spermatogonia in $\mathrm{Tex} 14^{+/-}$

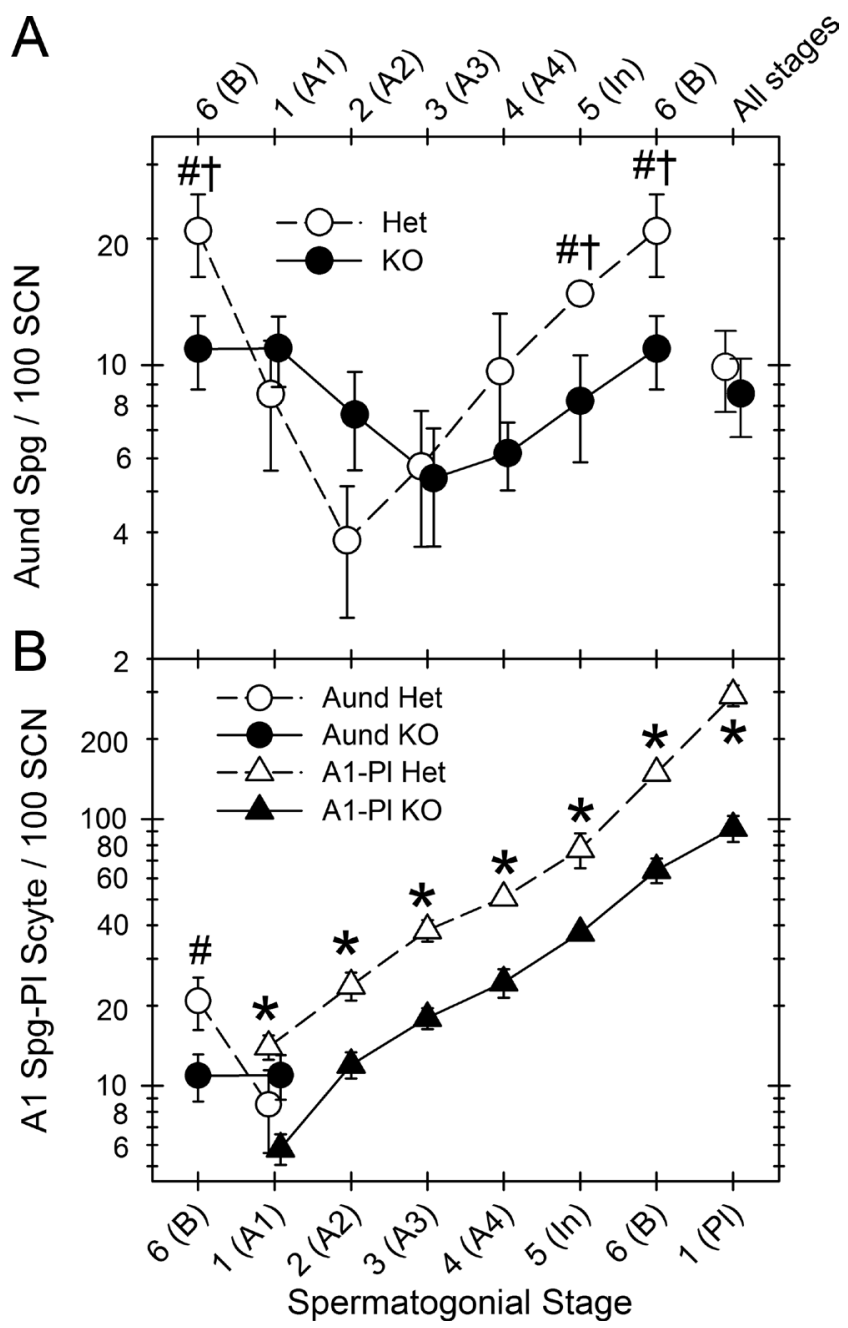

Figure 3 Numbers of type $A$ undifferentiated $\left(A_{\text {undiff }}\right)(A)$ and differentiating $\left(A_{1}, A_{2}, A_{3}, A_{4}, \ln , B\right)$ spermatogonia and preleptotene spermatocytes $(\mathrm{Pl})(\mathrm{B})$ in the six spermatogonial stages of the seminiferous epithelium of Tex $14^{+/-}$(Het) and Tex $14^{-/}(\mathrm{KO})$ mice. In (A) the numbers of $\mathrm{A}_{\text {undiff }}$ spermatogonia averaged over all stages is also shown. In (B), the numbers of $A_{\text {undiff }}$ spermatogonia are shown at stages 6 and 1 to compare with the numbers of $A_{1}$ spermatogonia. Spg, spermatogonia; Scyte, spermatocyte; SCN, Sertoli cell nucleoli. $\left({ }^{*} P<0.05,{ }^{\sharp} P<0.09\right.$ between genotypes, $t$-test, ${ }^{+} P<0.05$, increase from minimum stage for that genotype, ANOVA, Tukey post hoc test). 
heterozygotes at the different stages ( $P=0.012$ ANOVA). The numbers of $A_{\text {undiff }}$ spermatogonia were the lowest at spermatogonial stage 2 (corresponding to stages IX to XI) (Fig. 3A); based on results with wild-type, these cells are likely $A_{\text {single }}$ and $A_{\text {paired. }}$. Significant expansion of the $A_{\text {undiff }}$ Occurred from spermatogonial stages 2 through 6 $(P<0.05)$, as more $A_{\text {paired }}$ and longer chains of $A_{\text {aligned }}$ spermatogonia are produced. Then, between stages 6 and 2, the numbers of $A_{\text {undiff }}$ decreased sharply as the differentiation-primed cells, which are largely $A_{\text {aligned, }}$ differentiate into $A_{1}$ spermatogonia throughout stage 1 .

The total number of type $A_{\text {undiff }}$ spermatogonia in the Tex $14^{-/-}$mutants, averaged over all stages, was similar to that observed in heterozygotes (Fig. 3A), suggesting that the self-renewing pool of SSCs is well preserved in Tex $14^{\%}$ mice. In Tex $14^{-\%}$ homozygous mutants, there were trends in the expansion and reduction by differentiation of the $A_{\text {undiff }}$ spermatogonial pool that were similar to those observed in heterozygotes, but the increases and decreases appeared smaller than in the heterozygotes. However, these trends did not reach statistical significance at $P<0.05$, in part because each of the four mutant animals analyzed had quite different numbers of $A_{\text {undiff }}$ spermatogonia (Supplementary Fig. $1 A$ and $B$, see section on supplementary materials given at the end of this article). However, when the data at different stages were normalized to the average number of $A_{\text {undiff }}$ spermatogonia in each animal, there was indeed a significant increase in the numbers of $A_{\text {undiff }}$ spermatogonia between the minimum at stage 3 and the amount at stage 6 , and also a significant decrease between stages 1 and 3 (Supplementary Fig. 1C). In addition, the increase in numbers of $\mathrm{A}_{\text {undiff }}$ between the minimum and stage 6 was less in the Tex $14^{-/}$mutant than in the heterozygotes (amounting to 54\% of that in the heterozygote), and the decline between stage 6 and stages 1 and 2 was not as great in the Tex $14^{-\%}$ mutant as in the heterozygotes (Supplementary Fig. 1C). These results suggest that there might be some defect in Tex $14^{-1-}$ mice in the ability of $A_{\text {undiff }}$ to increase their numbers during stages 3 to 6 . In addition, the less pronounced decrease in $\mathrm{A}_{\text {undiff }}$ spermatogonia in the Tex $14^{-/-}$mutants between stages 6 and 2, suggests that the $A_{\text {undiff }}$ did not progress to a state where they could be as efficiently recruited to form $A_{1}$ spermatogonia as in heterozygotes.

Both the lower numbers of $A_{\text {undiff }}$ in stage 6 and the less pronounced reduction in numbers through stage 1, account for the numbers of differentiating type $A_{1}$ spermatogonia in Tex $14^{-/-}$mutants, being only $46 \%$ of the value in heterozygotes at stages 1 and 2 $(P<0.05)$ (Fig. 3B). The subsequent proliferation and differentiation from $A_{2}$ to In spermatogonia occurred normally in Tex $14^{-1}$ mutants, as these cells' numbers increased proportionally for both genotypes. The spermatogonial numbers in the mutant mice remained at $48 \%$ of those in heterozygotes $(P<0.05)$ through the In spermatogonial stage (Fig. 3B). Although B spermatogonia and preleptotene spermatocytes increase in numbers in stages 6 and 1, the ratio of these cells in Tex $14^{-/}$mutants to that in heterozygotes declined to $32 \%$ by stage 1 .

The nuclear morphology of preleptotene (Fig. 4B), leptotene (Fig. 4C), zygotene, and early-to-midpachytene spermatocytes (Fig. 4A) appeared normal under HRLM in Tex $14^{-\%}$ mutant mice. In more advanced mid-pachytene spermatocytes, fine abnormal chromatin condensation was observed (Fig. 4B) and subsequently coarse granular chromatin and cytoplasm with apoptotic
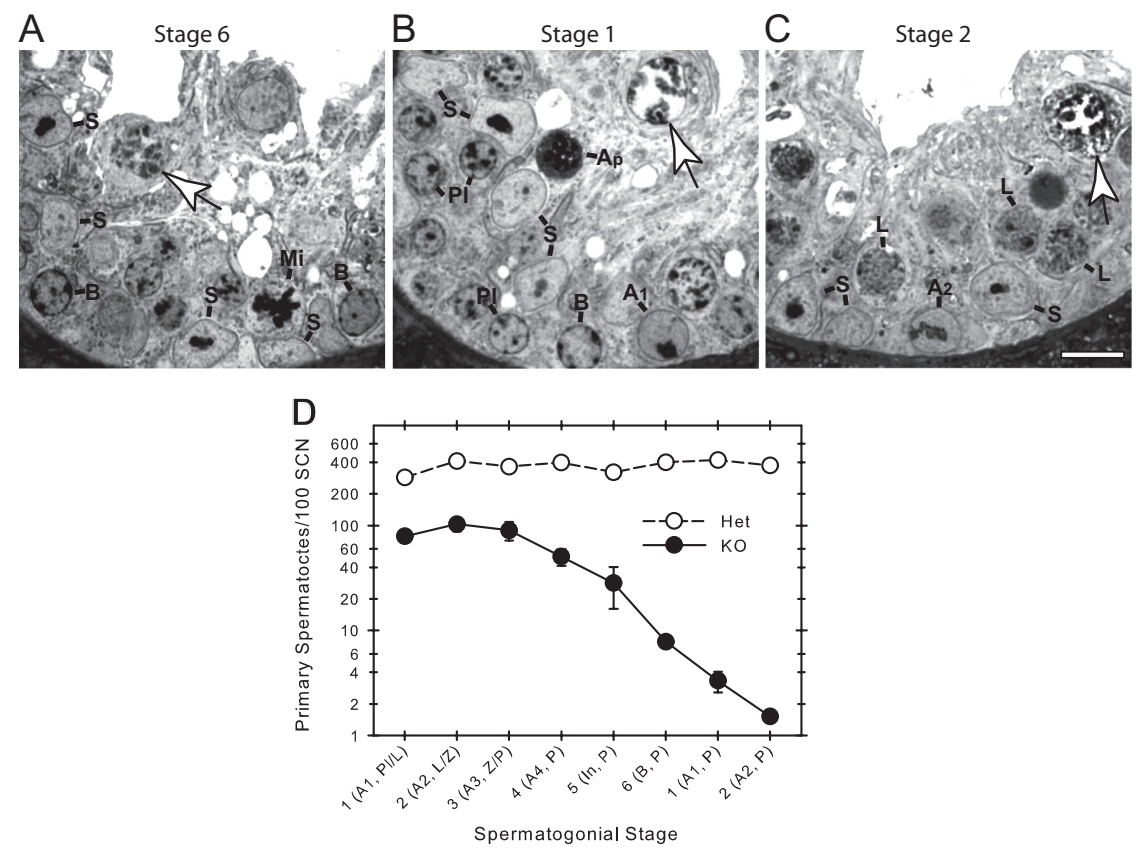

Figure 4 Photomicrographs of Tex $14 \%$ mice testes showing middle pachytene spermatocyte (A; white arrow) with normal appearance while the more advanced pachytene cells ( $B$ and $\mathrm{C}$; white arrows) showed progressive degenerative appearance. S, Sertoli cell; $M i$, mitosis; Ap, apoptosis; $A_{1}, A_{2}$, type $A_{1}$ and $A_{2}$ spermatogonia; Pl, preleptotene; $L$, leptotene; Z, zygotene; P, pachytene spermatocytes. Bar: $12 \mu \mathrm{m}$. (D) Numbers of primary spermatocytes in the spermatogonial stages of the seminiferous epithelial cycle. Het, heterozygous; $\mathrm{KO}$, Tex $14^{-/}$mice; SCN, Sertoli cell nucleoli. 
appearance were detected (Fig. 4C). The total numbers of primary spermatocytes present in Tex $14^{-/}$mice were maintained at about $30 \%$ of the number in the heterozygotes until the appearance of zygotenes in stage 3 (Fig. 4D). Thereafter, pachytene spermatocytes were progressively depleted to less than $1 \%$ of the number in heterozygotes animals by spermatogonial stage 6 (corresponding to stages IV to VI). Spermatids were rarely seen in the $T e x 14^{-\%}$ testes.

\section{Germ cell asynchrony}

Based on the description of the spermatogonial stages of the seminiferous epithelial cycle, B spermatogonia should be only found in stage 6 tubules, which lack other differentiating spermatogonia, and preleptotene spermatocytes should be found only in tubules at spermatogonial stage 1 , associated with type $A_{1}$ spermatogonia. This was almost exclusively the case in Tex $14^{+/}$heterozygotes. However in Tex $14^{-/}$mutants, we detected more type B spermatogonia (Fig. 5A) and preleptotene spermatocytes (Fig. 5B) in tubules that also harbored type $A_{2}$ spermatogonia. In Fig. 5B both the expected cells, leptotene spermatocytes, and earlier stage preleptotene, were observed, indicating most likely that the cells in leptotene showed normal development but the preleptotene cells were delayed in development.

To quantify the level of synchrony, we examined the percentages of each specific differentiating spermatogonial and spermatocyte (up to zygotene) types within tubules at the six different spermatogonial stages (Fig. 6). In Tex $14^{+/}$heterozygotes, as expected, a high degree of synchrony was observed as at least $84 \%$ of spermatogonia or spermatocytes were positioned within the stage primarily associated with that cell type; only $16 \%$ or less the cells were found in other stages, which were always adjacent to the peak stage. In the Tex $14^{-1}$ mutants, there was almost no loss of synchrony from $\mathrm{A}_{1}$ to In spermatogonia. However, asynchrony was first observed starting at the B spermatogonial stage as
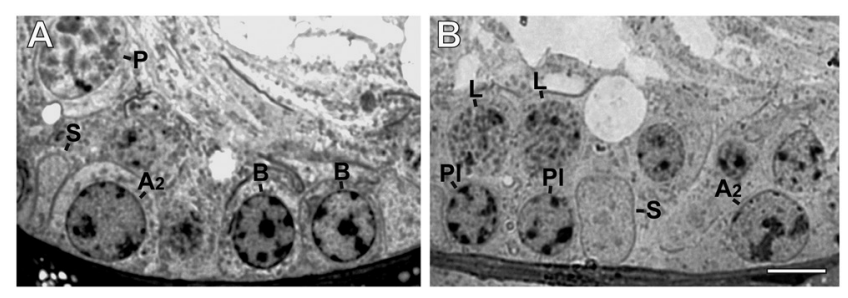

Figure 5 Photomicrographs showing spermatogonial asynchrony in Tex $14^{\%}$ mice, in which B spermatogonia (A) and preleptotene spermatocytes (B) are observed in the same section of the seminiferous tubule with type $A_{2}$ spermatogonia. Normally the $B$ spermatogonia are associated with $\mathrm{A}_{\text {undiff }}$ spermatogonia and preleptotene spermatocytes with A1 spermatogonia (Fig. 1). S, Sertoli cell; $A_{2}, B$, Type $A_{2}$ and $B$ spermatogonia; Pl, preleptotene; $L$, leptotene; $Z$, zygotene; $P$, pachytene spermatocytes. Bar: $8 \mu \mathrm{m}$. between 41 and $63 \%$ of these cells were found in stages other than the peak stage. In general the asynchronous cells were found in stages later than the peak stage, indicating a delay in their differentiation kinetics as a result of the lack of intercellular bridges.

\section{Spermatogonial proliferation and apoptosis}

To evaluate the possible causes for reduction in the number of spermatogonia in Tex $14^{-1}$ mutants, associated with the loss of ICBs sbetween germ cells, we estimated spermatogonial proliferation and apoptosis. There was no significant difference between Tex 14 mutants and heterozygotes in the overall mitotic index of spermatogonia; however, when we evaluated the mitotic indices by spermatogonial stage, the proliferation in stages 1,2 , and 3 in the Tex $14^{-1}$ mice was significantly greater than in heterozygotes (Fig. 7A). The increase in mitotic activity was not necessarily due to $A_{1}$ or $A_{2}$ spermatogonial mitoses, which occurred during the expected stages, but may represent divisions of the numerous type B spermatogonia, which were delayed in their cycle progression and therefore present in those stages.

Tex $14^{+/}$heterozygotes showed a low number of apoptotic cells in the $A_{1}$ spermatogonial stage, with a small increase in the $A_{2}$ to $A_{4}$ spermatogonial stages (Fig. 7B), as previously reported in WT rodents (Huckins \& Oakberg 1978). In Tex14\%mutants, we observed a trend of increased spermatogonial apoptosis $(P=0.057)$ compared with heterozygotes during spermatogonial stages 6 and 1 (Fig. 7B). The increase in apoptosis at stage 6 is clearly due to the B spermatogonia, and the apoptotic increase at stage 1 is most likely due to B spermatogonia that were delayed in maturation.

BrdU labeling indices were used as a measure of cell proliferation, specifically transit through the S-phase of the cycle. Complete spermatogonial staging could not be done on the ethanol-fixed, methacrylate-embedded material that was required for the immunohistochemistry. The overall spermatogonial labeling indices was similar $(\sim 45 \%)$ in Tex $14^{+/-}$heterozygotes and Tex $14^{-/}$ mutants ( $P>0.05$; Fig. $7 \mathrm{C}$ and Supplementary Fig. 2$)$. To investigate the synchrony of cell cycle progression, we assessed the labeling indices in specific tubules and plotted the percentages of tubules within given ranges of labeling indices (Fig. 7D). If absolute synchrony were present, all spermatogonia in a tubule cross-section would either be in the S-phase of their cell cycle (BrdUlabeled) or in G2/M/G1 phases (BrdU-unlabeled). In the Tex $14^{+/-}$heterozygotes, there was indeed a bimodal distribution with tubules with low labeling indices $(<12.5 \%)$ and tubules with high labeling indices (62.5$87.5 \%)$, indicating a fairly high degree of synchrony. In contrast, in the Tex $14^{-/}$mutants the distribution was unimodal with about half of the tubules having intermediate labeling indices between 37.5 and $62.5 \%$, 

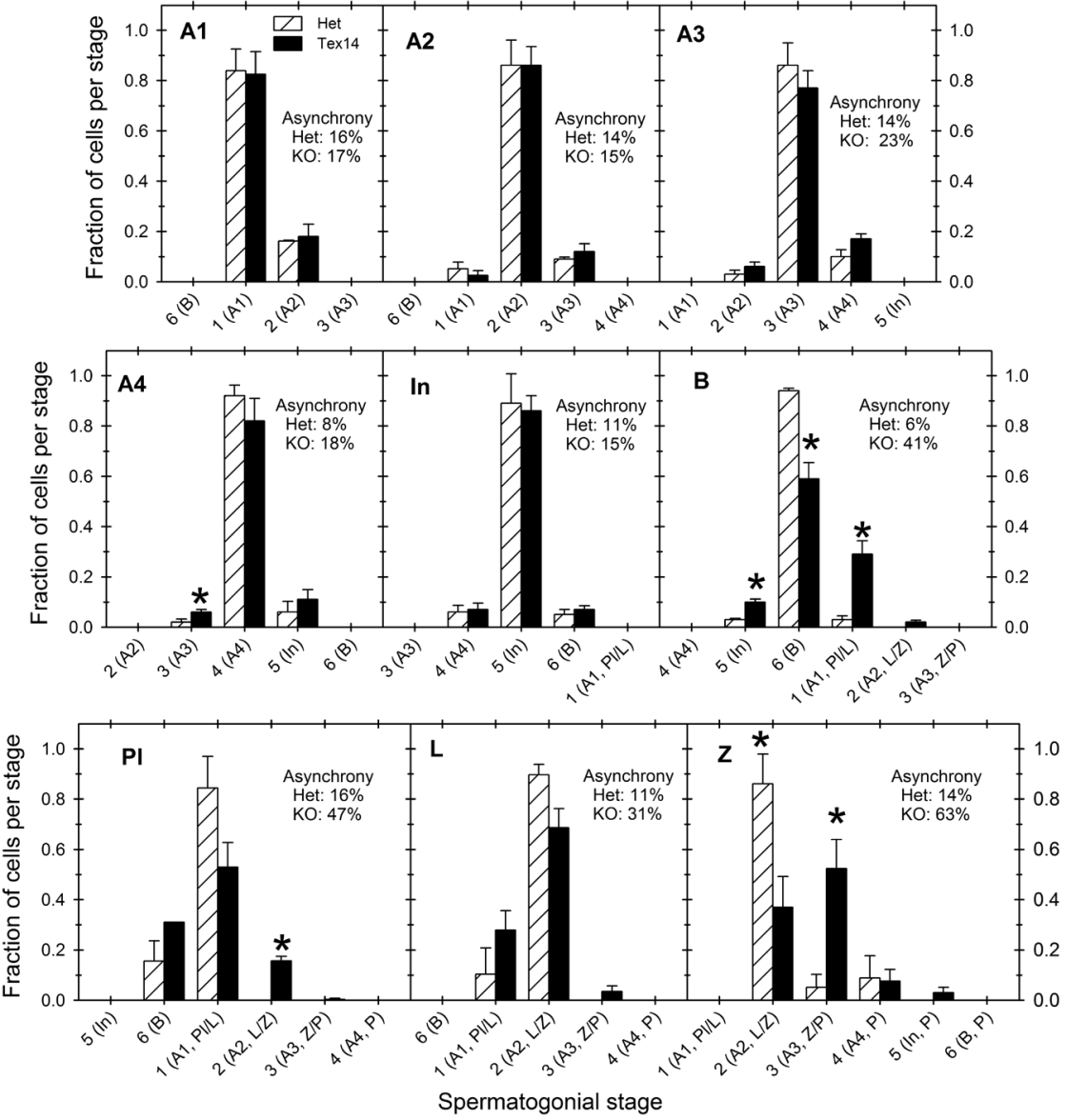

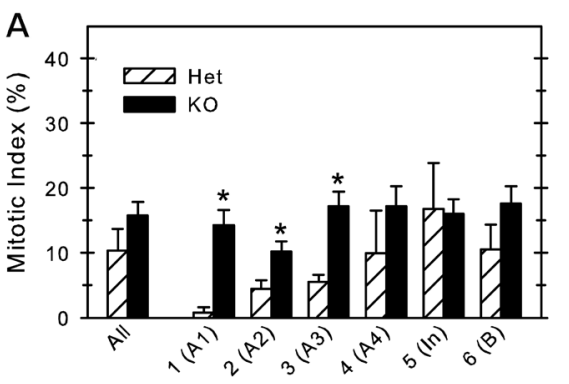

Spermatogonial Stage
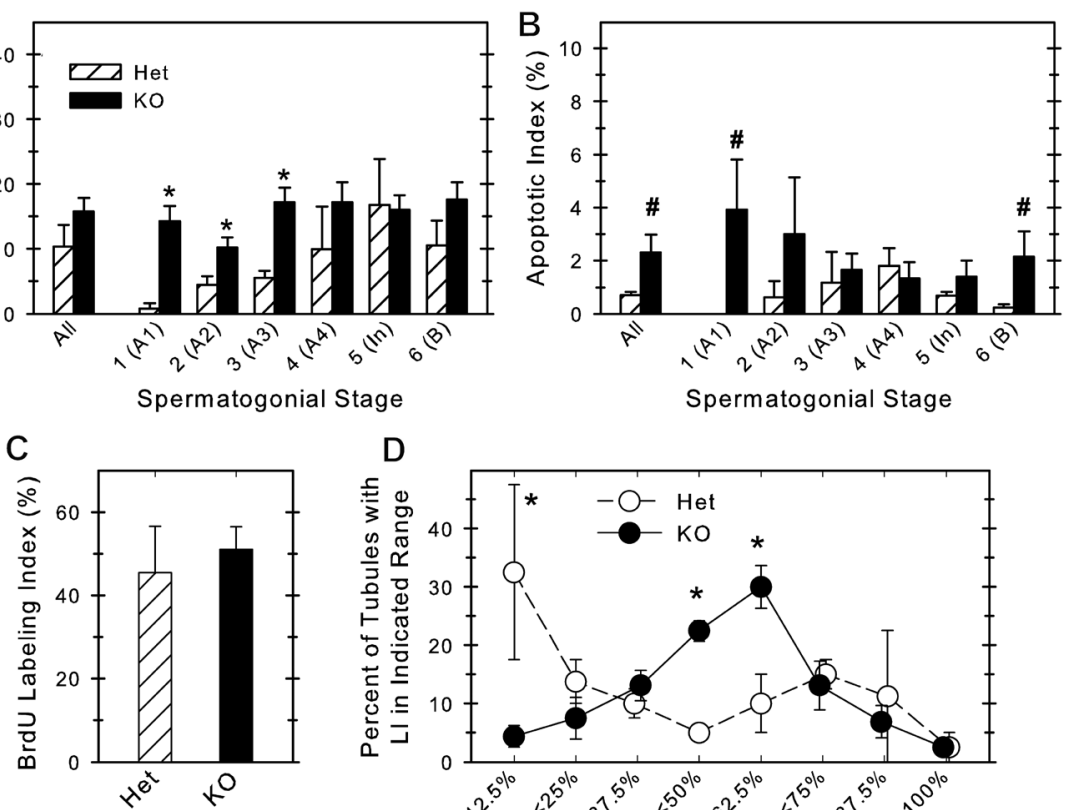

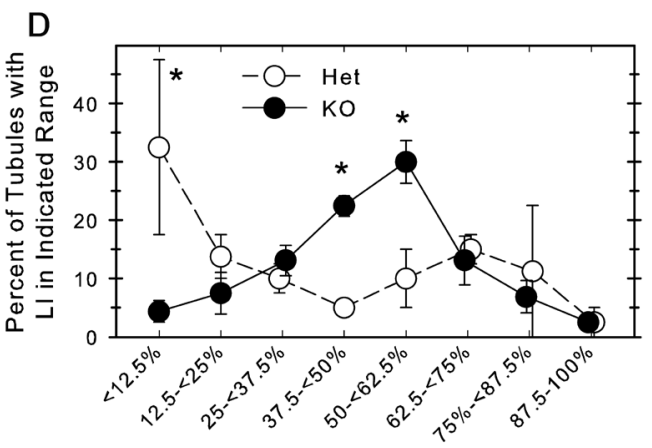

Range of $\mathrm{LI}$ of Spermatogonia in Tubules
Figure 6 Each panel shows the relative distribution of one spermatogonial or primary spermatocyte subtype along the 6 spermatogonial stages in Tex $14^{+/}$(Het) and Tex $14^{-\%}$ (KO) mice. The stages, 1 through 6 , are labeled by the main cell types usually found in those stages. 'Asynchrony' was defined as the percentage of that type of cell found in tubules at other stages of the seminiferous epithelium cycle. In the heterozygous control mice $\geq 84 \%$ of cells are found in one stage. In the Tex $14^{-/}$mutants, the degree of asynchrony for $\mathrm{A}_{1}$ through In spermatogonia was similar to that in the heterozygote $(\leq 23 \%)$. The loss of synchrony occurred primarily at the type B spermatogonial stage ( $41 \%$ asynchrony). $\mathrm{Pl}$, preleptotene; L, leptotene; and Z, zygotene spermatocytes. (* significant difference, $P<0.05$, between genotypes).
Figure 7 Spermatogonial mitotic $(\mathrm{A})$ and apoptotic (B) indices in Tex $14^{+/}$(Het) and Tex $14^{\%}(\mathrm{KO})$ mice in the six spermatogonial stages, with the major spermatogonial cell type indicated. In studies of labeling index with BrdU (C), only an overall labeling index is presented, as spermatogonial staging could not be done in ethanol-fixed, methacrylateembedded tissue. (D) The percentages of seminiferous tubules within eight intervals, based on the BrdU labeling index (LI) of spermatogonia in individual tubule crosssections, is presented as a measure of synchrony. Note that in the Tex $14^{+/-}$ heterozygotes, there is a bimodal distribution with tubules with low labeling indices $(<12.5 \%)$ and tubules with high labeling indices $(62.5$ to $87.5 \%)$, indicating the tubules contain cells synchronized in the G2/M/G1 and in the S-phase of the cell cycle, respectively. In contrast, the Tex $14^{-/-}$mutants, show a unimodal distribution with intermediate labeling indices between $37.5 \%$ and $62.5 \%$. (* significant difference, $P<0.05$, between genotypes by $t$-test; \# nearly significant difference, $P=0.057$, between genotypes by Mann-Whitney $U$ test). 
indicating asynchronous passage through the cell cycle. Spermatogonial labelling indices were intermediate in tubules with low numbers of spermatogonia (likely $A_{1}$ to $A_{4}$ ) but were more greatly increased in tubules with high numbers of spermatogonia (likely In and B) (Supplementary Fig. 2). These results confirm the loss of spermatogonial synchrony in the Tex $14^{\%}$ mutants and even suggest that some cell cycle asynchrony occurs in type A spermatogonia. Because of the lack of ICBs in the Tex $14^{-/}$mutants, it is not possible to determine whether the asynchrony is within a given clone or between clones derived from different stem cells.

\section{Spermatogonial gene expression in whole-mount preparation of Tex14-mutant seminiferous tubule}

To analyze gene expression in Tex14 mutants, we utilized Tex $14^{+/+}$and Tex $14^{-/-}$mice carrying an Ngn3EGFP transgene (Yoshida et al. 2004). Consistent with endogenous Ngn3 mRNA expression in WT mice, the EGFP protein is observed in chains of $A_{\text {aligned }}$ spermatogonia, as well as a few $A_{\text {single }}$ and $A_{\text {paired }}$ cells (Yoshida et al. 2004). However, due to the long half-life of EGFP protein, the Ngn3-EGFP signal remains in differentiating spermatogonia, such that the $A_{\text {undiff }}$ spermatogonia are brightly fluorescent and the $A_{1}$ through intermediate spermatogonia become progressively dimmer (Yoshida et al. 2007).
In whole-mount preparations of $\mathrm{Tex} 14^{+/+}$; Ngn3EGFP seminiferous tubules, the density of Ngn3-EGFP+ spermatogonia fluctuates during the seminiferous epithelial cycle (Yoshida et al. 2007). Their density is the lowest in stages IV-VIII (spermatogonial stages 6 and 1 ), which contain the $A_{\text {undiff }}$ or $A_{1}$ spermatogonia that are relatively few in number but have the brightest EGFP fluorescence. Their density the highest in stages IX-III (spermatogonial stages 2-5), which contain $A_{2}$ to intermediate spermatogonia with dim fluorescence. Since the temporal order of the stages reflects on their spatial arrangement along the tubule length, the fluctuation of the density of Ngn3-EGFP ${ }^{+}$spermatogonia along the tubule length (Fig. 8A) corresponds to the wave of the seminiferous epithelium (Perey et al. 1961). In mutant Tex $14^{-1}$, Ngn3-EGFP tubules, the fluctuation in the density of Ngn3-EGFP+ ${ }^{+}$spermatogonia was also clearly observed (Fig. 8B), indicating that the spermatogenic wave is maintained in the absence of TEX14. Furthermore, it was apparent, especially in the areas where the Ngn3-EGFP+ ${ }^{+}$cells had low densities, that these cells were arranged in chains in $\mathrm{Tex} 14^{+/+}$mice but no chains were apparent in the Tex $14^{-/}$mice (Fig. $8 \mathrm{~A}$ and $\mathrm{B})$.

In WT mice, most of the $A_{\text {single }}$ and $A_{\text {paired }}$ which are the less differentiated of the $A_{\text {undiff }}$ spermatogonia, are GFR $1^{+}$but $\mathrm{NGN3}^{-}$, whereas most of the $\mathrm{A}_{\text {aligned, }}$ which are generally more primed for differentiation, are
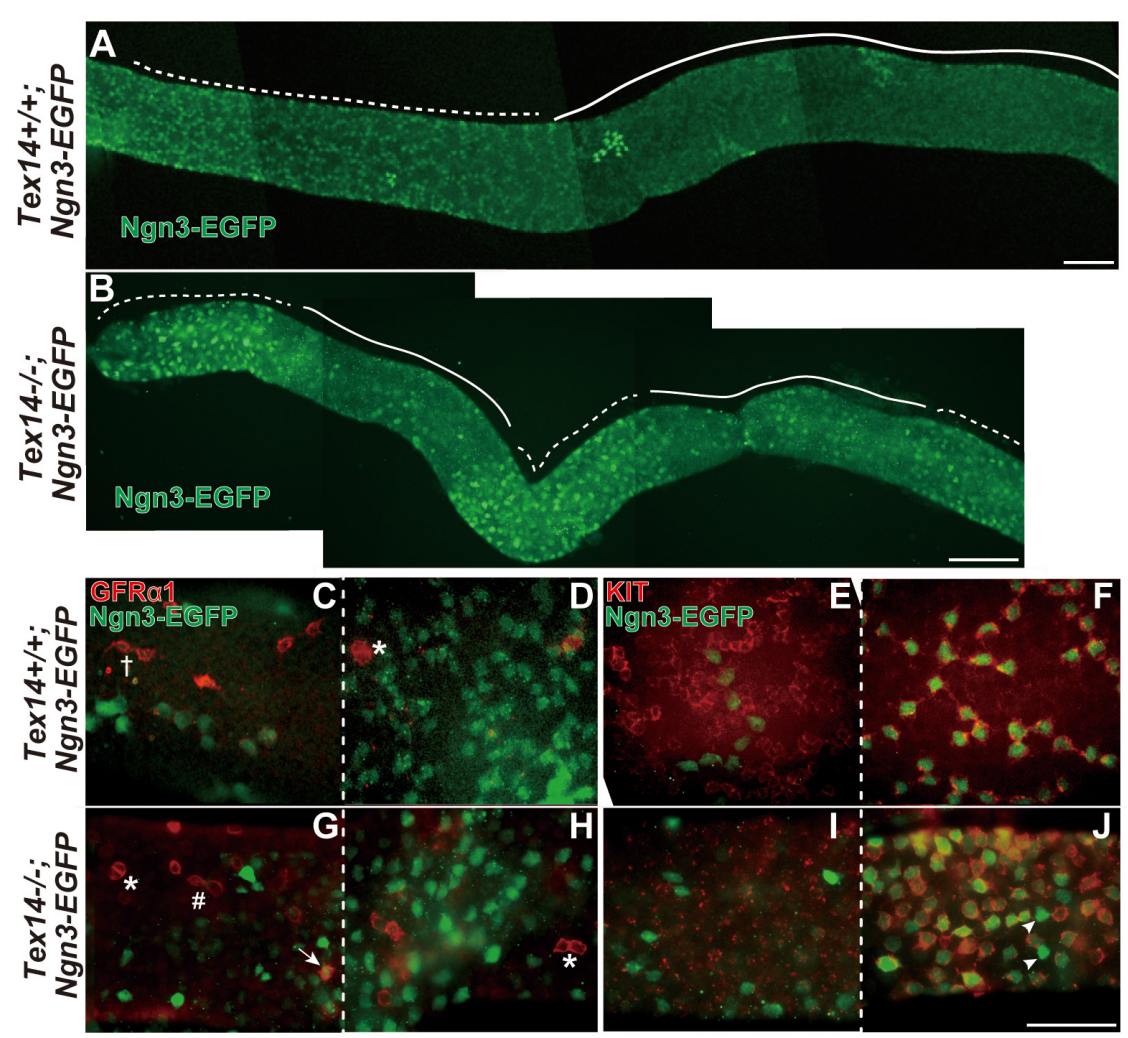

Figure 8 Gene expression patterns in spermatogonia revealed by whole-mount seminiferous tubule immunostaining. (A and B) Anti-GFP immunofluorescence (green) of whole-mounted seminiferous tubules showing the distribution of Ngn3-EGFP+ $P^{+}$spermatogonia along tubules in normal Tex14+/+; Ngn3-EGFP (A) and mutant Tex14\%; Ngn3-EGFP (B) mice. Solid and dotted lines indicate the regions harboring scarce and abundant Ngn3-EGFP ${ }^{+}$ cells, respectively. (C, D, E, F, G, H, I and J) Higher magnification of whole-mount immunofluorescence images using anti-GFP (green) and either anti-GFR $\alpha 1(C, D, G, H)$ or anti-KIT (E, F, I, J) antibodies (red) for the seminiferous tubule regions containing scarce (C, E, G, I) and abundant Ngn3-EGFP+ spermatogonia $(\mathrm{D}, \mathrm{F}, \mathrm{H}, \mathrm{J})$ in normal Tex $14^{+/+}$; Ngn3-EGFP (C, D, E and F) and mutant Tex $14^{-/} ; \operatorname{Ngn} 3-\operatorname{EGFP}(\mathrm{G}, \mathrm{H}, \mathrm{I}$ and $\mathrm{J})$ mice. Dot-like KIT signals in (I) may reflect the disappearing signals in preleptotene spermatocytes. Pairs of GFR $\alpha 1^{+}$spermatogonia in which multiple cells appear either clumped $(*)$, connected by a bridge (†) or connected by a foreshortened bridge $(\#)$ are indicated. The arrow (G) indicates a GFR 1 /Ngn3-EGFP double-positive spermatogonium. Arrowheads (J) indicate Ngn3-EGFP+/KIT- spermatogonia surrounded by numerous Ngn3-EGFP/KIT double-positive cells. Bars: $50 \mu \mathrm{m}$. 
GFR $\alpha 1^{-}$and $\mathrm{NGN3}^{+}$(Nakagawa et al. 2010, Hara et al. 2014). In Tex $14^{+/+}$mice as well as in Tex $14^{-/-}$mutants, GFR $\alpha 1^{+}$cells were predominantly observed as singles or pairs, and nearly all were NGN3-EGFP- (Fig. 8C, D, $\mathrm{G}$ and $\mathrm{H})$. Thus, the transition from $\mathrm{GFR} \alpha \mathrm{1}^{+}$to $\mathrm{Ngn}^{+}$ spermatogonia appears to occur normally in mice lacking TEX14. In Tex $14^{--}$mutants some GFR $\alpha 1^{+}$cells show occasional attachment with each other similar to $A_{\text {paired }}$ (Fig. 8G and $H$ ), but these may be cells that have just divided or crossed each other during migration (Hara et al. 2014).

In WT mice, the differentiating spermatogonia $\left(A_{1}\right.$, $\mathrm{A}_{2}, \mathrm{~A}_{3}, \mathrm{~A}_{4}$, In and B) form large syncytia of $\mathrm{KIT}^{+}$cells (Schrans-Stassen et al. 1999, Yoshida et al. 2004, Ikami et al. 2015, Carrieri et al. 2017). In tubule segments harboring scarce (although bright) Ngn3-EGFP+ cells (spermatogonial stages 6 and 1), the EGFP-bright, KIT $^{-}$cells are $A_{\text {aligned }}$ spermatogonia, whose chainlike appearance is more apparent in $\mathrm{Tex}_{14^{+/+}}$than in Tex $14^{-/-}$mice (Fig. 8E and I). In contrast, in segments harboring numerous (although less brightly fluorescent) Ngn3-EGFP ${ }^{+}$cells (spermatogonial stages 2 to 5) in both genotypes, most of these $\mathrm{EGFP}^{+}$cells are also $\mathrm{KIT}^{+}$ (Fig. 8F and J), which is expected since these EGFP-dim cells are $\mathrm{A}_{2}$ through intermediate spermatogonia. Long syncytia of Ngn3-EGFP $/ \mathrm{KIT}^{+}$cells are observed in the Tex $14^{+/+}$mice (Fig. 8F) but not in the Tex $14^{-/-}$mutants (Fig. 8J). In these segments, there are also some Ngn3$\mathrm{EGFP}^{+}$bright cells that are $\mathrm{KIT}^{-}$, as would be expected for $\mathrm{A}_{\text {undiff }}$ spermatogonia (Fig. 8J).

Thus, the arrangement of stages along the seminiferous tubules and the hierarchical composition of spermatogonia occur in an apparently normal manner and in Tex $14^{--}$mutant mice, reinforcing the histological findings that show normal morphological transitions of Tex $14^{-/}$spermatogonia.

\section{Discussion}

A major goal of this study was to characterize the events during the proliferative spermatogonial phase of spermatogenesis in Tex $14^{-/}$mutant mice with particular focus on the effects induced by the absence of the ICBs on the degree of synchrony of the germ cells.

The traditional $\mathrm{A}_{\mathrm{s}}$ model for stem cell self-renewal and differentiation, based on morphological investigations, suggests that the formation of the intercellular bridge is the first step of differentiation (Huckins 1971). More recent studies, revealing the heterogeneity in gene expression, suggest that some of the $\mathrm{A}_{\text {single }}$ cells are destined for differentiation (Nakagawa et al. 2010, Helsel et al. 2017), and some $A_{\text {paired }}$ and $A_{\text {aligned }}$ may still be capable of self-renewal via syncytial fragmentation (Hara et al. 2014). Although the extent of the contribution of syncytial fragmentation to stem cell dynamics is still controversial, there is agreement that the stem cell potential is related to the transcriptional or epigenetic state of the $\mathrm{A}_{\text {single }}$ cells (Lord \& Oatley 2017, Yoshida 2019). However, functional studies of whether or not being isolated is a causal factor for a spermatogonium to maintain stem cell potential were lacking.

The results in this study unambiguously demonstrate that the type A spermatogonia lacking TEX14, which remain singly isolated, undergo qualitatively normal differentiation, indicating that formation of the ICB is not essential for differentiation. Rather, it may be a consequence of the normal differentiation program of the cells, which is defined by their gene expression. This conclusion is consistent with the current stem cell models. In the revised $\mathrm{A}_{\mathrm{s}}$ model, the decision whether to self-renew or differentiate occurs in a subset of $A_{s}$ cells without establishing the interconnection (Lord \& Oatley 2017). In the fragmentation model the commitment to differentiate can occur both in $\mathrm{A}_{\mathrm{s}}$ and syncytial GFR $\alpha 1^{+}$ spermatogonia (Hara et al. 2014). These models are not mutually exclusive and it is important to determine the relative contributions of the different sequences to stem cell renewal in the steady state. Although self-renewal of stem cells in Tex $14^{--}$mutants was demonstrated functionally by the presence of spermatogonia in 1-yearold mice (Greenbaum et al. 2006), future in-depth studies of Tex14 mutants are still warranted to further elucidate the dynamics of this process.

The hierarchical differentiation sequence of spermatogonia from being GFRA $1^{+}$to becoming $\mathrm{NGN}^{+}{ }^{+}$ GFRA $1^{-}$and subsequently to being $\mathrm{KIT}^{+}$was identical in heterozygotes and in Tex $14^{-/-}$mutants (Fig. 8). However the rate of increase of $A_{\text {undiff }}$ spermatogonia in the stages corresponding to expansion of the $\mathrm{A}_{\text {aligned }}$ appeared lower in the Tex $14^{-/-}$mutants (Fig. 3A), but the differences did not achieve statistical significance. Comparison of gene expression in spermatogonia isolated from adult Tex $14^{-1}$ mutant testes with WT showed no changes in some markers of $A_{\text {single }} / A_{\text {paired }}$ spermatogonia such as Nanos2 and $B c / 6 b$, but there was a reduction in expression of Id 4 and an increase in Gfra 1 and Ret in the mutants (Iwamori et al. 2012).

The first statistically significant difference in cell numbers between Tex $14^{\%}$ mutants and heterozygotes was the reduced number of $A_{1}$ spermatogonia formed during the transition from $A_{\text {undiff }}$ spermatogonia at stage 1. In normal mice, differentiation-primed $A_{\text {undiff, which }}$ are largely $\mathrm{A}_{\text {aligned }}$ cells expressing Ngn3, are recruited to become $A_{1}$ spermatogonia, whereas the $A_{\text {single }}$ and most of the $A_{\text {paired }}$ which are largely NGN3 negative, remain undifferentiated (Huckins \& Oakberg 1978, Ikami et al. 2015, Carrieri et al. 2017). Despite the fact that the expression of NGN3 is qualitatively similar in stages 6 to 1 in the two genotypes (Fig. 8C and G), a lower percentage of spermatogonia in Tex $14^{-/-}$mutants, than in Tex $14^{+/-}$heterozygotes, transform into $\mathrm{A}_{1}$ cells at between stages 6 to 1 (Fig. 3B). The high concentration of retinoic acid at spermatogonial stage 1 (stages VIIVIII) (Endo et al. 2015 and Hogarth et al. 2015) and 
expression of appropriate retinoic acid receptors in the $\mathrm{A}_{\text {undiff }}$ spermatogonia (Ikami et al. 2015, Lord et al. 2018) are responsible for the $A_{\text {undiff }}$ to $A_{1}$ transition. The differentiation defect is unlikely to be due to lack of retinoic acid production in the Tex14 mutants, because the $A_{\text {undiff }}$ to $A_{1}$ transition can be promoted by Sertoli-cell produced retinoic acid in the absence of pachytene spermatocytes (Vernet et al. 2006, Sugimoto et al. 2012, Endo et al. 2015). Hence the differentiation defect of $\mathrm{A}_{\text {undiff }}$ observed in the Tex $14^{-/}$mutant mice are quite likely to be intrinsic to the spermatogonia. In the absence of the ICBs, the signals generated in a few $\mathrm{A}_{\text {undiff }}$ cells are not shared or exchanged to other cells and thus the synchronous induction of differentiation to $A_{1}$ cells is dampened.

Next we observed that the proliferation and differentiation of the $\mathrm{A}_{1}$ cells in Tex $14^{--}$mutant mice appears relatively normal as the numbers of cells in subsequent mitotic stages, through In spermatogonia, increased proportionately to that observed in heterozygotes (Fig. 3B). A1-In spermatogonia were localized in the expected stages of the seminiferous epithelial cycle (Fig. 6). However, when the mutant spermatogonia developed to the type B stage, they were present in several different stages or the seminiferous epithelial cycle. In particular, many type B spermatogonia remained in stage 1, indicating that their further progression was delayed. The prevalence of tubules with intermediate percentages of BrdU labeling in the Tex $14^{-/-}$mutants (Fig. 7D) confirms the overall spermatogonial cell cycle asynchrony in Tex $14^{-/}$mutant spermatogonia. Although cell count in the stages indicted that synchronous differentiation is maintained through In spermatogonia and the asynchrony first becomes noticeable in the B spermatogonia, the BrdU labeling suggest that some cell-cycle asynchrony was already present at earlier stages. Differences in the expression of cyclins and cyclin-dependent kinase inhibitors were observed between cultured spermatogonia from Tex $14^{-1-}$ mutant and from heterozygous mice (Iwamori et al. 2012), might be causally related to the asynchrony observed in Tex $14^{-/-}$mutant spermatogonial differentiation.

In addition to ICBs, long, thin cytoplasmic projections (CP) connecting spermatogonia at the same stage of development have recently been described in both WT and Tex $14^{-/}$mutant mice (Niedenberger et al. 2018). The CPs can exchange cytoplasmic factors between cells and could maintain some of the functions lost by the eradication of ICBs in and Tex $14^{-/}$mutants and account for the development of spermatogonia in these mutants. However, our data show that CPs, if they play auxiliary roles for ICBs, are not enough to maintain a normal spermatogonial yields and synchrony of progression, which were compromised in Tex $14^{-/-}$mutants.

In conclusion, the present study showed that the development of cells in the spermatogonial compartment occurs in the absence of ICBs. However, the synchronous recruitment of most of the $A_{\text {undiff }}$ cells to form $A_{1}$ spermatogonia and the synchrony of the spermatogonial cell cycle and differentiation divisions are quantitatively attenuated. These results demonstrate that one function of the ICBs is to maintain the synchrony of development of spermatogenic cells.

\section{Supplementary materials}

This is linked to the online version of the paper at https://doi. org/10.1530/REP-20-0118.

\section{Declaration of interest}

The authors declare that there is no conflict of interest that could be perceived as prejudicing the impartiality of the research reported.

\section{Funding}

This study was partially supported by the following Brazilian organizations: Coordenação de Aperfeiçoamento de Pessoal de Nível Superior (CAPES), Fundação de Amparo à Pesquisa do Estado de Minas Gerais (FAPEMIG) and Conselho Nacional de Desenvolvimento Científico e Tecnológico (CNPq). This study was also supported in part by the Ministry of Education, Culture, Sports, Science and Technology (MEXT; KAKENHI JP20116004, JP26450453, JP15H01523, JP25114004, and JP16H02507), Japan. Support for creation and analysis of the Tex14 KO mice has come from the Eunice Kennedy Shriver National Institute of Child Health and Human Development (R01HD088412 and P01HD087157 to M M M ) and the Bill \& Melinda Gates Foundation (INV-001902 to M M M).

\section{Author contribution statement}

Tissue collection, data acquisition and analysis: C A R-M, A L C-B and A L D-B; data interpretation: all authors; manuscript drafting, research conception and design, $S \mathrm{Y}$, M L M and H C-G, critical revision: G M B, G S, K H, F R C L A and $\mathrm{MMM}$; research supervision: $\mathrm{ML} \mathrm{M}$ and $\mathrm{HC}-\mathrm{G}$. Approval of the final version: all authors.

\section{Acknowledgements}

Some microscopic analysis were performed in the Centro de Aquisição e Processamento de Imagens (CAPI - ICB/UFMG).

\section{References}

Abercrombie M 1946 Estimation of nuclear population from microtome sections. Anatomical Record 94 239-247. (https://doi.org/10.1002/ ar.1090940210)

Braun RE, Behringer RR, Peschon JJ, Brinster RL \& Palmiter RD 1989 Genetically haploid spermatids are phenotypically diploid. Nature 337 373-376. (https://doi.org/10.1038/337373a0)

Carrieri C, Comazzetto S, Grover A, Morgan M, Buness A, Nerlov C \& O'Carroll D 2017 A transit-amplifying population underpins the efficient 
regenerative capacity of the testis. Journal of Experimental Medicine $\mathbf{2 1 4}$ 1631-1641. (https://doi.org/10.1084/jem.20161371)

Chiarini-Garcia H \& Meistrich ML 2008 High-resolution light microscopic characterization of spermatogonia. Methods in Molecular Biology 450 95-107. (https://doi.org/10.1007/978-1-60327-214-8_6)

Chiarini-Garcia H \& Russell LD 2001 High-resolution light microscopic characterization of mouse spermatogonia. Biology of Reproduction 65 1170-1178. (https://doi.org/10.1095/biolreprod65.4.1170)

Chiarini-Garcia H, Parreira GG \& Almeida FRCL 2011 Glycol methacrylate embedding for improved morphological, morphometrical, and immunohistochemical investigations under light microscopy: testes as a model. Methods in Molecular Biology 689 3-18. (https://doi. org/10.1007/978-1-60761-950-5_1)

de Rooij DG 2017 The nature and dynamics of spermatogonial stem cells. Development 144 3022-3030. (https://doi.org/10.1242/dev.146571)

Dym M \& Fawcett DW 1971 Further observations on the numbers of spermatogonia, spermatocytes, and spermatids connected by intercellular bridges in the mammalian testis. Biology of Reproduction 4 195-215. (https://doi.org/10.1093/biolreprod/4.2.195)

Endo T, Romer KA, Anderson EL, Baltus AE, de Rooij DG \& Page DC 2015 Periodic retinoic acid-STRA8 signaling intersects with periodic germ-cell competencies to regulate spermatogenesis. PNAS 112 E2347-E2356. (https://doi.org/10.1073/pnas.1505683112)

Greenbaum MP, Yan W, Wu MH, Lin YN, Agno JE, Sharma M, Braun RE, Rajkovic A \& Matzuk MM 2006 Tex14 is essential for intercellular bridges and fertility in male mice. PNAS 103 4982-4987. (https://doi. org/10.1073/pnas.0505123103)

Hamer G, Roepers-Gajadien HL, Gademan IS, Kal HB \& de Rooij DG 2003 Intercellular bridges and apoptosis in clones of male germ cells. International Journal of Andrology 26 348-353. (https://doi.org/10.1111/ j.1365-2605.2003.00436.x)

Hara K, Nakagawa T, Enomoto H, Suzuki M, Yamamoto M, Simons BD \& Yoshida S 2014 Mouse spermatogenic stem cells continually interconvert between equipotent singly isolated and syncytial states. Cell Stem Cell 14 658-672. (https://doi.org/10.1016/j.stem.2014.01.019)

Helsel AR, Yang QE, Oatley MJ, Lord T, Sablitzky F \& Oatley JM 2017 ID4 levels dictate the stem cell state in mouse spermatogonia. Development 144 624-634. (https://doi.org/10.1242/dev.146928)

Hogarth CA, Arnold S, Kent T, Mitchell D, Isoherranen N \& Griswold MD 2015 Processive pulses of retinoic acid propel asynchronous and continuous murine sperm production. Biology of Reproduction 9237. (https://doi.org/10.1095/biolreprod.114.126326)

Huckins C 1971 The spermatogonial stem cell population in adult rats. I. Their morphology, proliferation and maturation. Anatomical Record 169 533-557. (https://doi.org/10.1002/ar.1091690306)

Huckins C 1978 Spermatogonial intercellular bridges in whole-mounted seminiferous tubules from normal and irradiated rodent testes. American Journal of Anatomy 153 97-121. (https://doi.org/10.1002/ aja.1001530107)

Huckins C \& Oakberg EF 1978 Morphological and quantitative analysis of spermatogonia in mouse testes using whole mounted seminiferous tubules: I. The normal testes. Anatomical Record 192 519-528. (https:// doi.org/10.1002/ar.1091920406)

Ikami K, Tokue M, Sugimoto R, Noda C, Kobayashi S, Hara K \& Yoshida S 2015 Hierarchical differentiation competence in response to retinoic acid ensures stem cell maintenance during mouse spermatogenesis. Development 142 1582-1592. (https://doi.org/10.1242/dev.118695)

Iwamori N, Iwamori T \& Matzuk MM 2012 Characterization of spermatogonial stem cells lacking intercellular bridges and genetic replacement of a mutation in spermatogonial stem cells. PLOS ONE 7 e38914. (https://doi.org/10.1371/journal.pone.0038914)

Lord T \& Oatley JM 2017 A revised Asingle model to explain stem cell dynamics in the mouse male germline. Reproduction 154 R55-R64. (https://doi.org/10.1530/REP-17-0034)

Lord T, Oatley MJ \& Oatley JM 2018 Testicular architecture is critical for mediation of retinoic acid responsiveness by undifferentiated spermatogonial subtypes in the mouse. Stem Cell Reports 10 538-552. (https://doi.org/10.1016/j.stemcr.2018.01.003)

Moens PB \& Hugenholtz AD 1975 The arrangement of germ cells in the rat seminiferous tubule: an electron-microscope study. Journal of Cell Science 19 487-507.

Morales CR, Lefrancrois S, Chennathukuzhi V, El-Alfy M, Wu X, Yang J, Gerton GL \& Hecht NB 2002 A TB-RBP and Ter ATPase complex accompanies specific mRNAs from nuclei through the nuclear pores and into intercellular bridges in mouse male germ cells. Developmental Biology 246 480-494. (https://doi.org/10.1006/dbio.2002.0679)

Nakagawa T, Sharma M, Nabeshima Y, Braun RE \& Yoshida S 2010 Functional hierarchy and reversibility within the murine spermatogenic stem cell compartment. Science 328 62-67. (https://doi.org/10.1126/ science.1182868)

Niedenberger BA, Cook K, Baena V, Serra ND, Velte EK, Agno JE, Litwa KA, Terasaki M, Hermann BP, Matzuk MM et al. 2018 Dynamic cytoplasmic projections connect mammalian spermatogonia in vivo. Development 145 1-8. (https://doi.org/10.1242/dev.161323)

Perey BY, Clermont Y \& Leblond CP 1961 The wave of the seminiferous epithelium in the rat. American Journal of Anatomy 108 47-77. (https:// doi.org/10.1002/aja.1001080105)

Ren HP \& Russell LD 1991 Clonal development of interconnected germ cells in the rat and its relationship to the segmental and subsegmental organization of spermatogenesis. American Journal of Anatomy 192 121-128. (https://doi.org/10.1002/aja.1001920203)

Russell LD 1977 Movement of spermatocytes from the basal to adluminal compartments of the rats testis. American Journal of Anatomy $\mathbf{1 4 8}$ 313-328. (https://doi.org/10.1002/aja.1001480303)

Russell LD, Ettlin RA, Hikim APS \& Clegg ED 1990 Histological and Histopathological Evaluation of the Testis. Clearwater, FL: Cache River Press.

Schrans-Stassen BH, van de Kant HJ, de Rooij DG \& van Pelt AM 1999 Differential expression of c-kit in mouse undifferentiated and differentiating type A spermatogonia. Endocrinology 140 5894-5900. (https://doi.org/10.1210/endo.140.12.7172)

Sugimoto R, Nabeshima Y \& Yoshida S 2012 Retinoic acid metabolism links the periodical differentiation of germ cells with the cycle of Sertoli cells in mouse seminiferous epithelium. Mechanisms of Development 128 610-624. (https://doi.org/10.1016/j.mod.2011.12.003)

Tegelenbosch RA \& de Rooij DG 1993 A quantitative study of spermatogonial multiplication and stem cell renewal in the $\mathrm{C} 3 \mathrm{H} / 101$ $\mathrm{F}_{1}$ hybrid mouse. Mutation Research 290 193-200. (https://doi. org/10.1016/0027-5107(93)90159-d)

Ventela S, Toppari J \& Parvinen M 2003 Intercellular organelle traffic through cytoplasmic bridges in early spermatids of the rat: mechanisms of haploid gene product sharing. Molecular Biology of the Cell $\mathbf{1 4}$ 2768-2780. (https://doi.org/10.1091/mbc.e02-10-0647)

Vernet N, Dennefeld C, Guillou F, Chambon P, Ghyselinck NB \& Mark M 2006 Prepubertal testis development relies on retinoic acid but not rexinoid receptors in Sertoli cells. EMBO Journal 25 5816-5825. (https:// doi.org/10.1038/sj.emboj.7601447)

Weber JE \& Russell LD 1987 A study of intercellular bridges during spermatogenesis in the rat. American Journal of Anatomy 180 1-24. (https://doi.org/10.1002/aja.1001800102)

Wu MH, Rajkovic A, Burns KH, Yan W, Lin YN \& Matzuk MM 2003 Sequence and expression of testis-expressed gene 14 (Tex14): a gene encoding a protein kinase preferentially expressed during spermatogenesis. Gene Expression Patterns 3 231-236. (https://doi. org/10.1016/s1567-133x(03)00036-x)

Yoshida S 2019 Heterogeneous, dynamic, and stochastic nature of mammalian spermatogenic stem cells. Current Topics in Developmental Biology 135 245-285. (https://doi.org/10.1016/ bs.ctdb.2019.04.008)

Yoshida S, Sukeno M \& Nabeshima Y 2007 A vasculature-associated niche forum differentiated spermatogonia in the mouse testis. Science $\mathbf{3 1 7}$ 1722-1726. (https://doi.org/10.1126/science.1144885)

Yoshida S, Takakura A, Ohbo K, Abe K, Wakabayashi J, Yamamoto M, Suda T \& Nabeshima Y 2004 Neurogenin3 delineates the earliest stages of spermatogenesis in the mouse testis. Developmental Biology 269 447-458. (https://doi.org/10.1016/j.ydbio.2004.01.036)

Received 3 March 2020

First decision 6 April 2020

Revised manuscript received 24 April 2020

Accepted 14 May 2020 